\title{
Impacts of hydrate on the lateral stress in sediments
}

\author{
Jongchan Kim ${ }^{1}$, Haitao Zhang ${ }^{1,2}$, Yongkoo Seol ${ }^{3}$, and Sheng Dai ${ }^{1, *}$ \\ ${ }^{1}$ Geosystems Engineering, Georgia Institute of Technology, 790 Atlantic Drive, Atlanta, GA, USA \\ ${ }^{2}$ School of Naval, Ocean and Architecture Engineering, Shanghai Jiao Tong University, Shanghai, China \\ ${ }^{3}$ National Energy Technology Laboratory, Morgantown WV, USA
}

\begin{abstract}
The ratio between the horizontal and the vertical effective stresses is defined as the coefficient of earth pressure at rest $K_{0} . K_{0}$ in hydrate-bearing sediments is critical in understanding the stress states in hydrate-bearing sediments, yet has not been previously understood. An oedometer cell equipped with vertical and horizontal stress measurement sensors is used to measure the evolution of $K_{\mathrm{o}}$ in tetrahydrofuran hydratebearing sands during hydrate formation and dissociation and vertical stress changes. The results show that the response of $K_{\mathrm{o}}$ in hydrate-bearing specimens reflects the combined effects of hydrate cementation, the viscous nature of hydrate crystals, and the stress levels. These results can enhance the understanding of stress anisotropy and geomechanical behaviors of hydrate reservoirs during gas production.
\end{abstract}

\section{Introduction}

The coefficient of earth pressure at rest $K_{\mathrm{o}}$ indicates the in situ stress state in deposits, and can be defined as the ratio of vertical and horizontal effective stress, as expressed below,

$$
K_{o}=\frac{\sigma_{h}^{\prime}}{\sigma_{v}^{\prime}}
$$

where $\sigma_{v}^{\prime}$ and $\sigma_{h}^{\prime}$ are the vertical and horizontal effective stresses. The value of $K_{o}$ in soils can be influenced by many factors, including the effective stress, stress history, the over-consolidation ratio, cementation bonding and debonding, packing density, and particle shape and size [1-5].

For non-cemented soils, the values of $K_{\mathrm{o}}$ does not change significantly during loading, i.e., the lateral stress increases linearly with the increase in vertical stress [2,3]. The response of the $K_{\mathrm{o}}$ of cemented soils is different from that of the non-cemented soils. For cemented soils, the $K_{o}$ is mainly governed by the cementation among particles during loading, leading to lower $K_{o}$ values at low strain conditions $[2,6]$.

The hydrate crystals in pore spaces can play an essential role in the stress-strain relation, strength, stiffness, permeability, and volume changes of hydratebearing specimens [7-10]. Especially, the increased effective stress caused by the depressurization method for gas production in deep-sea hydrate deposits can induce significant changes in the $K_{o}$ of hydrate-bearing sediments. Therefore, it is essential to understand the affecting factors of the values of $K_{o}$ in hydrate-bearing sediments.

The objective of this experimental study is to investigate the evolution of $K_{o}$ in tetrahydrofuran (THF) hydrate-bearing specimens and to understand the effects of hydrate crystals on the stress state under zero lateral strain condition.

\section{Experimental setup}

Fig.1 shows a schematic drawing of a thick-wall oedometer cell (refer to $[11,12]$ for more details of this setup). The vertical stress is controlled the hydraulic pump in a reaction frame, and a diaphragm pressure transducer installed at the middle height of the specimen monitors the lateral stress response. Porous bronze disks are embedded on the pedestals to allow uniform drainage of the pore fluid throughout the test. The whole experimental setup is placed into a freezer to control the experimental temperature with an accuracy of $0.1^{\circ} \mathrm{C}$.

F110 fine quartz sands (maximum void ratio $e_{\max }=$ 0.85 , minimum void ratio $e_{\min }=0.54$, mean particle size $d_{50}=120 \mu \mathrm{m}$, and uniformity coefficient $C_{u}=1.21$ ) are used in this experimental study. The specimens have a diameter of $50.8 \mathrm{~mm}$, and a height of $30.5 \mathrm{~mm}$ with the relative packing density $D_{r}=40 \%$ and the corresponding void ratio $e=0.726$. The ratio of specimen height and diameter $(\mathrm{H} / \mathrm{D})$ is limited to 0.6 to prevent the boundary effects from the top and bottom pedestals [13]. The F110 sands are mixed with a predetermined ratio of THF and deionized water. The mass ratio of THF and deionized water is $0: 100$ for $S_{h}=0$ (water-saturated) and 20.3:79.7 for $S_{h}=0.96$ specimens.

After packing, the specimen temperature is lowered to $0.1^{\circ} \mathrm{C}$ to trigger hydrate formation. During the hydrate formation, $25 \mathrm{kPa}$ vertical stress, caused by the selfweight of the top pedestals, is applied to the specimens. Once a thermal peak indicating the initiation of hydrate nucleation is observed, the temperature is kept constant for at least additional 24 hours. Meanwhile, the vertical

\footnotetext{
* Corresponding author: sheng.dai@ce.gatech.edu
} 
displacement, lateral stress, and P-wave velocity are continually monitored to confirm the completion of hydrate formation. After hydrate formation, additional vertical stress is applied stepwise to the specimens up to $25 \mathrm{MPa}$. Each loading step is applied at a rate of approximately $5 \mathrm{MPa}$ per minute until the targeted vertical stress is achieved and then held constant. The lateral stress is measured throughout the hydrate formation and the loading processes.

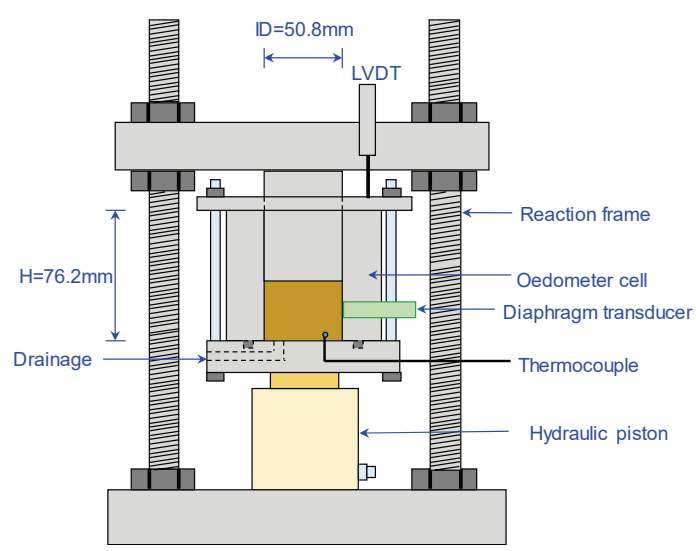

Fig. 1. A schematic drawing of the instrumented oedometer cell for lateral stress measurement.

\section{Experimental results}

Fig.2 shows the time-lapse temperature, horizontal stress, and calculated $K_{\mathrm{o}}$ during hydrate formation in the $S_{\mathrm{h}}=0.96$ sediment. The initiation of hydrate crystallization is indicted by the thermal spike. No vertical deformation is observed during hydrate formation. However, the lateral stress increases from approximately $15 \mathrm{kPa}$ up to about $35 \mathrm{kPa}$ and gradually decreases, under a constant vertical stress of $25 \mathrm{kPa}$. Thus, the calculated $K_{\mathrm{o}}$ shows the same time-lapse trend.
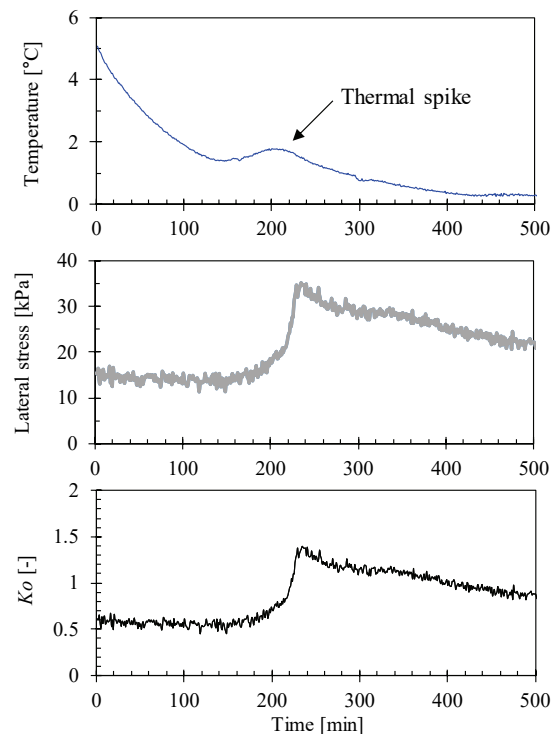

Fig. 2. Evolution of temperature, horizontal stress, and $K_{0}$ during hydrate formation.
Fig.3 presents the evolution of vertical and lateral stresses and the corresponding $K_{o}$ response with elapsed time during the stepwise loading. The $S_{h}=0$ sediment shows a slight decrease in $K_{0}$ at the moment of each loading step and then stabilizes in minutes. For the $S_{h}=$ 0.96 sediment, the temporary reduction followed by a gradual increase in $K_{o}$ is observed during each loading step.

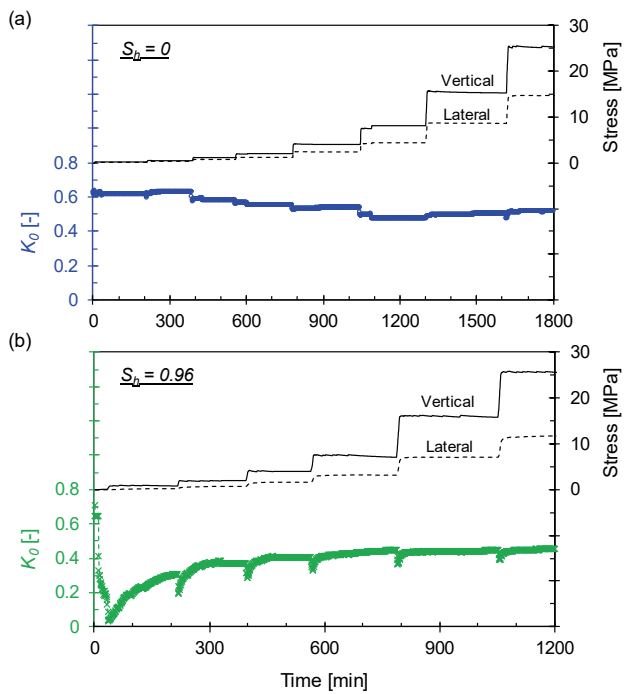

Fig. 3. Experimental results of the time-lapse vertical and horizontal stresses in the tested specimens. (a) $S_{h}=0$ (watersaturated) sediment. (b) $S_{h}=0.96$ (hydrate-bearing) sediment.

\section{Discussion}

The response of $K_{o}$ during loading is summarized in Fig. 4. For $S_{h}=0$ (water-saturated) specimen, $K_{o}$ slightly decreases with increasing vertical stress. The minor reduction in $K_{o}$ indicates a stiffer specimen, attributed to the compaction effects by the increased vertical stress.

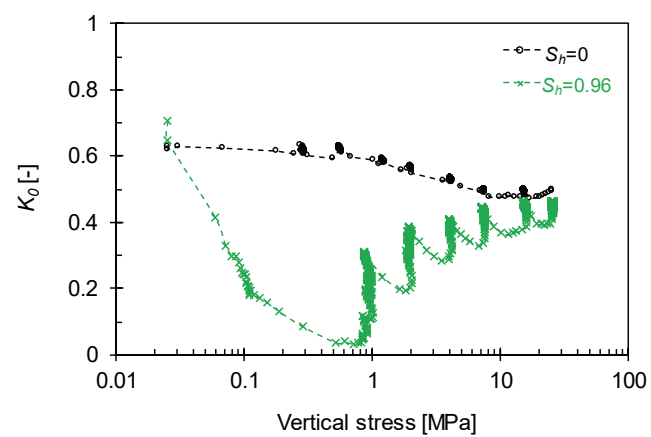

Fig. 4. Changes in the coefficient of earth pressure at rest $K_{0}$ of $S_{h}=0$ (black circle markers) and 0.96 (green cross markers) specimens during loading. The loading process starts from 0.025 $\mathrm{MPa}$ and up to $25 \mathrm{MPa}$.

The hydrate-bearing sediments $S_{h}=0.96$ show a significant reduction of $K_{0}$ at the low vertical stress level $\left(\sigma_{v}<1 \mathrm{MPa}\right)$. A lower $K_{o}$ value indicates a less pronounced stress transfer from the vertical to the lateral direction. With further increase of vertical stress, the $K_{o}$ 
firstly decreases at the moment of vertical loading and then rises under a constant vertical load, indicating a viscous behavior in stress transfer. Since no such evident time-lapse behavior is detected in the $S_{h}=0$ specimen, it can be concluded that the presence of hydrate crystals causes such a creep behavior in the $K_{o}$ of the hydratebearing specimen. Since quarzitic sands do not present significant creep behaviors [14], the observed apparent time-delayed response of stress transfer in hydratebearing sediments highlights the critical role of hydrate crystals in the stress state of hydrate-bearing sediments.

The hydrate crystals can enhance the strength and the stiffness of hydrate-bearing specimens [15-17]. The reduction of $K_{o}$ for the $S_{h}=0.96$ specimen under relatively low vertical stress $\left(\sigma_{v}<1 \mathrm{MPa}\right)$ is primarily caused by the cementation between soil particles and hydrate crystals. The cementation supports and shares the applied verticals stress and causes less pronounced lateral stress transfer [2, $4,7]$. Also, hydrate crystals can act as part of the skeletal structure that carries the load together with soil particles [16]. At relatively high vertical stress $\left(1 \mathrm{MPa}<\sigma_{v}<25\right.$ $\mathrm{MPa}$ ), the $K_{o}$ of the hydrate-bearing specimen is mainly governed by the sand skeleton after losing the majority of cementation.

\section{Conclusions}

This study experimentally examines the evolution of the coefficient of earth pressure at rest $K_{o}$ in hydratebearing specimens. The main findings follow.

- The $K_{\mathrm{o}}$ of the hydrate-free specimen $\left(S_{h}=0\right.$, watersaturated) decreases slightly from 0.63 to 0.51 as the vertical stress increases from $25 \mathrm{kPa}$ to $25 \mathrm{MPa}$, mainly due to the compaction effect that stiffens the specimen.

- The hydrate-bearing specimen $\left(S_{h}=0.96\right)$ shows a significant reduction in $K_{o}$, reflecting the role of hydrate crystals in bonding the sand particles and thus less stress transfer in the horizontal direction.

- The presence of hydrate crystals plays a vital role in the viscous response of $K_{o}$ during loading.

- With further increases in the vertical stress, the $K_{o}$ value increases, mainly governed by the sand skeleton after the debonding of hydrate cementation.

The work is supported by the DOE/NETL gas hydrate research program.

\section{References}

1. Andrawes, K.Z. and M.A. El-Sohby, Factors affecting coefficient of earth pressure Ko. Journal of Geotechnical and Geoenvironmental Engineering, 1973. 99(7): p. 527-539.

2. Yun, T.S. and T.M. Evans, Evolution of at-rest lateral stress for cemented sands: experimental and numerical investigation. Granular Matter, 2011. 13(5): p. 671.

3. Brooker, E.W. and H.O. Ireland, Earth pressures at rest related to stress history. Canadian geotechnical journal, 1965. 2(1): p. 1-15.
4. Zhu, F., J.I. Clark, and M.J. Paulin, Factors affecting at-rest lateral stress in artificially cemented sands. Canadian geotechnical journal, 1995. 32(2): p. 195203.

5. Wanatowski, D. and J. Chu, KO of sand measured by a plane-strain apparatus. Canadian Geotechnical Journal, 2007. 44(8): p. 1006-1012.

6. Lee, J., et al., Effect of freezing and thawing on $K_{0}$ geostatic stress state for granular materials. Granular Matter, 2016. 18(3): p. 69.

7. Yun, T.S. and J.C. Santamarina, Decementation, softening, and collapse: changes in small-strain shear stiffness in $k 0$ loading. Journal of Geotechnical and Geoenvironmental engineering, 2005. 131(3): p. 350-358.

8. Boswell, R., J. Yoneda, and W.F. Waite, India National Gas Hydrate Program Expedition 02 summary of scientific results: Evaluation of natural gas-hydrate-bearing pressure cores. Marine and Petroleum Geology, 2019. 108: p. 143-153.

9. Waite, W.F., et al., Physical properties of hydrate bearing sediments. Reviews of geophysics, 2009. 47(4).

10. Lee, J., J.C. Santamarina, and C. Ruppel, Volume change associated with formation and dissociation of hydrate in sediment. Geochemistry, Geophysics, Geosystems, 2010. 11(3).

11. Kim, J., et al., Compressibility and particle crushing of Krishna-Godavari Basin sediments from offshore India: Implications for gas production from deepwater gas hydrate deposits. Marine and Petroleum Geology, 2019. 108: p. 697-704.

12. Kim, J., et al., Particle crushing in hydrate-bearing sands. Geomechanics for Energy and the Environment, 2019: p. 100133.

13. Shin, H. and J.C. Santamarina, Mineral dissolution and the evolution of $k$ 0. Journal of Geotechnical and Geoenvironmental Engineering, 2009. 135(8): p. 1141-1147.

14. Yamamuro, J.A., P.A. Bopp, and P.V. Lade, Onedimensional compression of sands at high pressures. Journal of geotechnical engineering, 1996. 122(2): p. 147-154.

15. Yun, T., et al., Compressional and shear wave velocities in uncemented sediment containing gas hydrate. Geophysical Research Letters, 2005. 32(10).

16. Yoneda, J., et al., Strengthening mechanism of cemented hydrate - bearing sand at microscales. Geophysical Research Letters, 2016. 43(14): p. 74427450 .

17. Hyodo, M., et al., Undrained monotonic and cyclic shear response and particle crushing of silica sand at low and high pressures. Canadian Geotechnical Journal, 2016. 54(2): p. 207-218. 